\title{
Non-stationary drying of ceramic-like materials controlled through acoustic emission method
}

\author{
Stefan Jan Kowalski • Justyna Szadzińska
}

Received: 22 October 2011 / Accepted: 17 June 2012/Published online: 10 July 2012

(C) The Author(s) 2012. This article is published with open access at Springerlink.com

\begin{abstract}
This paper presents results of convective drying of ceramic-like materials in non-stationary conditions. The effect of periodically changing drying parameters at different frequencies and amplitudes on material quality has been investigated. During drying tests the destruction of the material was controlled trough the acoustic emission method and monitored with a digital camera. The experiments were carried out on cylindrically shaped samples made of KOC kaolin clay. The non-stationary drying consisted in periodical changes of the drying medium temperature and humidity. It has been found that a properly arranged methodology of non-stationary drying positively affects the product quality, mainly when drying is carried on with periodical changes of air humidity and to lesser extent with periodical changes of air temperature.
\end{abstract}

\section{Introduction}

Saturated capillary-porous materials such as ceramics or wood often experience fractures during drying when the process is carried on improperly [1-4]. Therefore, a great care should be paid to adequate arrangement of such a process, particularly in industry of quality goods, to avoid cracking of the dried products. Fractured products are of bad quality and sometimes even disqualified from further practical usage.

\section{S. J. Kowalski $(\bowtie) \cdot J$ J. Szadzińska}

Institute of Technology and Chemical Engineering, Poznań

University of Technology, pl. Marii Skłodowskiej-Curie 2,

60-965 Poznan, Poland

e-mail: Stefan.J.Kowalski@ put.poznan.pl

J. Szadzińska

e-mail: justyna.szadzinska@doctorate.put.poznan.pl
In an attempt to enhance heat and mass transfer during drying, to preserve quality, and to minimize energy consumption, a substantial amount of research has been focused on the identification of innovative heating and drying processes. One of the recommended techniques for drying of solids for which internal heat and mass transfer rates control the drying kinetics is time-dependent or intermittent drying $[5,6]$. Supplying heat intermittently rather than continuously can be done by interrupting the air flow to provide the material a "rest" period, by a continuous air flow periodically heated, or by periodic reduction of air flow. Intermittent heating allows more time for the internal moisture to diffuse to the surface of the material when no heat or a reduced level of heating is supplied. In the subsequent drying period, the drying rate can then be higher without raising the solids temperature excessively. In intermittent heating, drying air is continuous, while heating is periodically "on" and "off" to provide the material a tempering period.

A favorable impact of various cyclic and intermittent variation of the drying air temperature on drying kinetics and product quality parameters has been demonstrated in works $[6,7]$. In these papers, various intermittent drying schemes have been selected to optimize the set of operating parameters to enhance drying kinetics, product quality parameters and heat recovery during heat pump drying. The heat pump drying is employed to study the optimization process of heat-sensitive products. It is noteworthy that such a framework may be applied to other drying systems for different products.

Another mode of intermittent drying consists of continuous heat supply over a predetermined period (usually down to the critical moisture content), a tempering period over which redistribution of temperature and moisture content takes place with essentially no heat supply, and continuous drying down to the final moisture content $[8,9]$. 
Chen [10] demonstrated that the drying and tempering phase duration significantly affected the drying rate of rough rice in intermittent drying. In addition, factors such as drying air temperature, drying air humidity, drying air flow rate per unit mass of crop, the rice variety, as well as initial and final rice moisture content affect the quality of batch re-circulating drying. Notably, the drying and the tempering phase duration significantly affect the drying rate of rough rice in intermittent drying. For this type of drying, a few thin layer equations have been developed [11]. According to these results, the drying rate of rough rice is extremely fast during initial drying stage, as attributed mainly to a quick moisture release from the rice hull. Moreover, related investigations derived thin layer equations to describe the drying rate in this period, i.e., about 5-15 min from the start of drying.

Dried materials sustain destruction because of dryinginduced stresses. Such stresses arise when a non-uniform distribution of moisture and/or temperature in the material is created [12-15]. The greater is the non-uniformity in moisture and/or temperature distribution, the greater stresses are induced. The analysis of moisture distribution during drying carried out in these papers allows to state that the greatest moisture heterogeneity occurs mostly at the end of the constant drying rate period (CDRP), that is, when the surface layer becomes dry, and the material core is still saturated. At this stage of drying the material cracking is the most likely to occur, especially when the drying rate is high and the drying material is thick. For this reason, the process should be slowed down at the end of the CDRP to enable a better moisture distribution inside the pores of the material, and thus to prevent the material destruction. But, in order not to lengthen the process too much, the drying rate should be increased again after a short period. Such a non-stationary process becomes then a remedy to avoid destruction of the material during drying [16-22].

Using a finite element model Zhang and Mujumdar [23] have simulated intermittent microwave drying of single grains. It was shown that there are reduced drying-induced stress fields that develop in this case when compared to continuous heating. During the off-period (when no heat is applied), the temperature and moisture fields have time to relax and relieve the stresses. The lower temperature and moisture gradients generated in intermittent drying also reduce drying stresses and resulting cracking of the grains. Li [24] examined fissuring of rough rice kernels both numerically and experimentally. He concluded that discontinuous drying does reduce stress cracking.

Jumah et al. [25] have shown experimentally and via mathematical modeling that spouting a bed of wet grain periodically by the air jet rotating slowly in a round vessel and by heating the spouting air periodically it is possible to reduce the net air consumption and energy required for drying by up to $35 \%$ white increasing the drying time only by up to $15 \%$. The main advantage in such a process is not just the reduced energy consumption but also the better product quality due to lower temperature of the drying material.

Shei and Chen [26] applied a partial differential equation model with newly-developed thin layer equations to simulate batch re-circulating dryers under different drying conditions, which are combinations of four parameters: drying air temperature, drying air absolute humidity, drying period duration, and tempering period duration. The moisture change and the drying rate, which were of particular concern with respect to the simulated data, were investigated. Validation drying tests were carried out in a lab scale re-circulating rice dryer. Comparing two experimental data with two simulated drying curves respectively, it revealed they are quite consist with each other under the same drying conditions. Drying air temperature, drying air humidity, drying period duration and tempering period duration significantly influenced the drying rate.

Kowalski and Pawłowski [27] developed a mathematical model describing complete drying kinetics, that is, both the drying curves and the evolution of dried body temperature, in stationary and non-stationary (intermittent) drying. Such a model enables optimization of drying processes with respect to drying time and to calculate the net energy consumption used for drying [28, 29].

A number of experimental drying tests with both periodically alternated temperature and humidity of the drying air were carried out by authors of this paper. The main aim of these studies was to analyze the effects of changes in frequency and amplitude of the drying air parameters on the final quality of dried products. The acoustic emission (AE) method was used to monitor and control these periodical processes, and the digital camera enabled optical visualization of the product quality [30-32]. The drying tests were realized on cylindrically shaped samples made of KOC kaolin provided by the Surmin Kaolin Company S.A., Nowogrodziec, Poland.

\section{Methodology}

\subsection{Experimental}

Experimental studies of drying at non-stationary conditions were carried out in the laboratory chamber dryer SML 42/250/M Zalmed (Poland), which enables convective drying with periodically alternated temperature and humidity of the drying air. The air temperature and relative humidity in the chamber were measured every half minute with a PT100 temperature probe and humidity sensor DO 
9861T Delta OHM (Italy). The digital indicator showed the air temperature with accuracy $0.1{ }^{\circ} \mathrm{C}$, while the air humidity was measured with accuracy of $0.01 \%$. The initial moisture content in the materials was determined using moisture analyzer model XM 120 Precisa (Switzerland). The periodical changes of air temperature in the dryer chamber were carried out by supplying cold air, and the air humidity changes were realized through steam supply. For this purpose the cooler model EVS060BED ECO Refrigerazione (Italy) and humidifier Nordmann Engineering AG (patent EP 0715 121P1, Switzerland), equipped with the vapor lance model WO 20/06, were used. The temporal changes of temperature and air humidity were programmed with the controller Moeller Easy 512-AC-RC. The stress development in the dried material were recorded by the $\mathrm{AE}$ method.

Figure 1 presents the scheme of the experimental equipment used for the tests.

The PMMA molder was used to form cylindrical samples of the radius $r=0.025 \mathrm{~m}$ and height $h=0.06 \mathrm{~m}$. For drying the kaolin samples were placed on the aluminum scale pan, to which the AE sensor was attached. The scale pan was hung on the electronic balance, model WPS 2100/C Radwag (Poland), to measure the weight loss with accuracy $0.01 \mathrm{~g}$. All measurements were recorded every half minute by the computer provided with a software and the data acquisition card.

At the beginning the drying test at stationary conditions $\left(T=100{ }^{\circ} \mathrm{C}\right)$ was carried out to identify the material

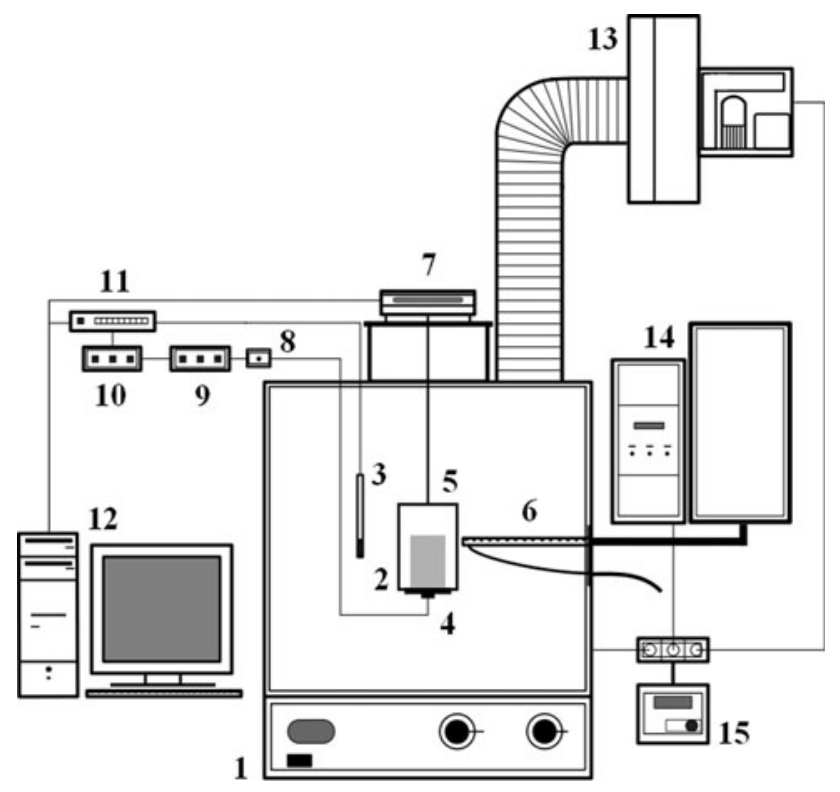

Fig. 1 The experimental setup: 1 dryer chamber, 2 sample, 3 temperature and humidity sensor, 4 transmitter of acoustic impulses, 5 scale pan, 6 vapor lance, 7 balance, 8 impulse converter, 9 preamplifier, 10 amplifier, 11 reading card, 12 computer, 13 cooler, 14 humidifier, 15 controller fracture commencement. The $\mathrm{AE}$ descriptors like total $\mathrm{AE}$ energy and total number of AE impulses were measured on-line during these tests to control the development of sample destruction.

Next two series of drying tests were carried out, first one at different frequencies and the other one with different amplitudes of the drying air temperature and humidity. The air temperature and humidity were controlled by the sensor located in the dryer chamber near the sample surface. Each experiment lasted $360 \mathrm{~min}$. Each time the samples were dried in stationary conditions at $T=100{ }^{\circ} \mathrm{C}$ for the first $2 \mathrm{~h}$ of the process. Periodical changes of the drying parameters were started before the end of the CDRP, that is, in c.a. $120 \mathrm{~min}$ of drying. The sequence of these parameters changes for different experiments are tabulated in Tables 1 and 2. The development of cracks was photographed every $10 \mathrm{~min}$ with a digital photo camera model DSC-H1 Sony (Poland). Each sample was weighted after drying using the analytical balance Explorer Pro Ohaus (Poland), photographed once again, and their external appearance was assessed visually.

\subsection{Acoustic emission (AE)}

The acoustic emission (AE) method, due to its nondestructive nature, is becoming very popular measurement and diagnostic technique in materials engineering. The $\mathrm{AE}$ arise mostly in stressed materials when elastic energy accumulated in these materials is released. The released energy is then transported throughout the material in the form of elastic waves propagating in various directions. It can be measured by the $\mathrm{AE}$ sensor installed at the material surface and registered through the AE descriptors like: AE energy per a time period (e.g. 30 s), total AE energy, total number of $\mathrm{AE}$ signals, etc. Knowing these descriptors, one can assess the intensity and number of micro- and macro-cracks [30-32]. The AE method is used in this paper to monitor material destruction during drying.

\subsection{Material}

The samples for experimental tests were made of KOC kaolin clay produced by the Surmin-Kaolin Company S.A., Nowogrodziec, Poland. The kaolin grains were initially in dry state and then grated into fine powder about $0.1 \mathrm{~mm}$. Then, the kaolin pulp was prepared by mixing the powder with a portion of water to get greasy paste of initial moisture content approximately $42 \%$, (dry basis). To level the moisture distribution in the material the greasy paste was stored in a closed box for $48 \mathrm{~h}$. The material was tested in the form of cylindrical samples of the radius $r=0.025 \mathrm{~m}$ and height $h=0.06 \mathrm{~m}$. 
Table 1 Frequency changes in the drying medium parameters

\begin{tabular}{|c|c|c|c|c|c|}
\hline $\begin{array}{l}\text { Sample } \\
\text { number }\end{array}$ & $\begin{array}{l}\text { Air temperature } \\
\text { changes }\end{array}$ & Number of cycles & $\begin{array}{l}\text { Sample } \\
\text { number }\end{array}$ & Air humidity changes & Number of cycles \\
\hline 1 & $\begin{array}{l}60 \text { min } \\
\text { cooling }+60 \mathrm{~min} \\
\text { heating }\end{array}$ & $\begin{array}{l}2 \text { cooling cycles }+2 \\
\text { heating cycles }\end{array}$ & 5 & $\begin{array}{l}30 \text { min } \\
\text { humidification }+60 \mathrm{~min} \\
\text { pause }\end{array}$ & $\begin{array}{l}3 \text { humidification cycles }+3 \text { cycles } \\
\text { without humidification }\end{array}$ \\
\hline 2 & $\begin{array}{l}50 \text { min } \\
\text { cooling }+30 \mathrm{~min} \\
\text { heating }\end{array}$ & $\begin{array}{l}3 \text { cooling cycles }+3 \\
\text { heating cycles }\end{array}$ & 6 & $\begin{array}{l}15 \text { min } \\
\text { humidification }+60 \mathrm{~min} \\
\text { pause }\end{array}$ & $\begin{array}{l}3 \text { humidification cycles }+3 \text { cycles } \\
\text { without humidification }\end{array}$ \\
\hline 3 & $\begin{array}{l}40 \text { min } \\
\text { cooling }+40 \mathrm{~min} \\
\text { heating }\end{array}$ & $\begin{array}{l}3 \text { cooling cycles }+3 \\
\text { heating cycles }\end{array}$ & 7 & $\begin{array}{l}5 \text { min } \\
\text { humidification }+30 \text { min } \\
\text { pause }\end{array}$ & $\begin{array}{l}8 \text { humidification cycles }+8 \text { cycles } \\
\text { without humidification }\end{array}$ \\
\hline 4 & Irregular changes & $\begin{array}{l}3 \text { cooling cycles }+3 \\
\text { heating cycles }\end{array}$ & 8 & Irregular changes & $\begin{array}{l}2 \text { humidification cycles }+2 \text { cycles } \\
\text { without humidification }\end{array}$ \\
\hline
\end{tabular}

Table 2 Presents the amplitude span of the drying medium parameters

\begin{tabular}{llll}
\hline $\begin{array}{l}\text { Sample } \\
\text { number }\end{array}$ & $\begin{array}{l}\text { Variable air } \\
\text { temperature }\left[{ }^{\circ} \mathrm{C}\right]\end{array}$ & $\begin{array}{l}\text { Sample } \\
\text { number }\end{array}$ & $\begin{array}{l}\text { Variable air } \\
\text { humidity [\%] }\end{array}$ \\
\hline 9 & Between 100 and 80 & 11 & $\begin{array}{l}\text { Between } 15 \text { and } \\
60\end{array}$ \\
10 & Between 100 and 60 & 12 & Between 5 and 40
\end{tabular}

\section{Drying with stable drying parameters}

First, the drying tests were carried out at constant temperature $100{ }^{\circ} \mathrm{C}$, which was rather high and ensured a high drying rate resulting in a short drying time. At the very beginning the air temperature in the dryer chamber was $100{ }^{\circ} \mathrm{C}$ and the humidity about $2.8 \%$. Next, during the heating period a slow increase of the air humidity to about $4.8 \%$ was registered. The humidity was kept almost constant during the CDRP when the evaporation of moisture proceeded as if from an open surface of liquid. Later, during the FDRP, the relative humidity decreased gradually due to slowing down of the drying rate. Thus, the selfvariation of the relative humidity made the drying conditions slightly unstable, even if the air temperature was kept constant (see also [21]).

High drying rate is favorable to material crack formation as the distribution of moisture content in such a process is highly nonlinear and involves a non-uniform shrinkage generating stresses in the drying material. These mechanical effects were monitored on line using the AE method [30-32]. The determined drying curves and the descriptors of $\mathrm{AE}$ total energy procured the basis for arranging the schedules of processes with variable drying parameters. The drying curve and the plot of total AE energy descriptor for high rate drying at stationary conditions are presented in Fig. 2.

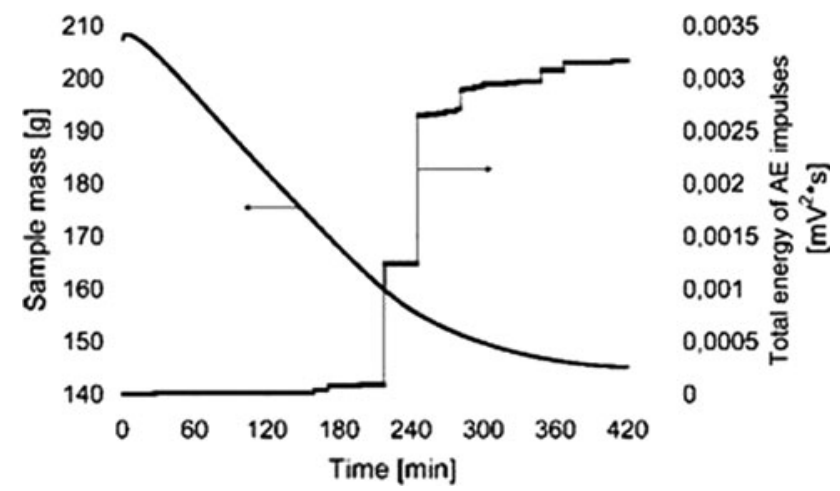

Fig. 2 The drying curve and the descriptor of total AE energy for drying at stable air temperature $100{ }^{\circ} \mathrm{C}$

The descriptor of total AE energy presented in Fig. 2 shows a rapid increase at the end of the CDRP, which was caused by a strong crack developed in the sample at that time. Due to material cracking, the elastic energy accumulated in the material was released and transported through the material to the sample surface, where it was registered by the $\mathrm{AE}$ sensor. Because of cracking a section of the AE energy curve goes upright. Next after cracking the material stops to emit AE energy until another portion of accumulated elastic energy is released. During this period a section of the AE energy curve becomes horizontal.

On the basis of the observed history of the AE energy, the schedules for changeable drying parameters were arranged. The starting point for changes of the drying conditions and slowing down the drying rate before the crack formation occurs was established. In this way one can avoid the material fracture and preserve a good quality of the dried sample. The quality of the sample dried at the stable temperature $100{ }^{\circ} \mathrm{C}$ was unsatisfied as the surface got a lot of smaller and bigger cracks (see Fig. 4a). 

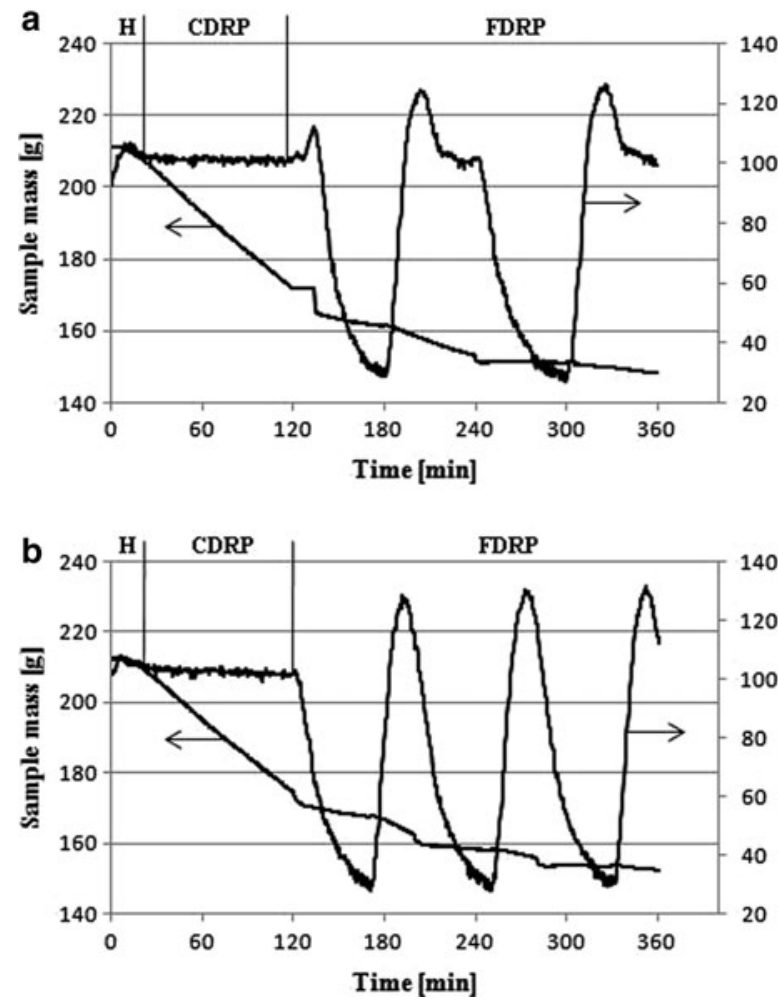

Fig. 3 Drying curves for periodical air temperature changes: a 60 min cooling +60 min heating, b 50 min cooling +30 min heating

\section{Drying with variable frequency of drying parameters}

4.1 Drying with variable frequency of temperature changes

In the first stage of the experimental studies the influence of the frequency changes of the drying medium parameters on the quality of dried samples was investigated. The aim of this part of the study was to find the frequency configuration that minimized fracture of this fragile material. The arrangement of periodical changes of the air temperature and humidity was based on the measurement the total $\mathrm{AE}$ energy and the total number of AE impulses emitted by the sample dried in stationary conditions $\left(T=100{ }^{\circ} \mathrm{C}\right)$, which was presented in the previous section. The moments on drying curves at which the sample revealed increased emission of acoustic signals indicated the beginning of periodical changes of drying parameters. Eight experiments were carried out altogether. The changes of air parameters and also the number of cycles in the falling drying rate periods (FDRP) are shown in Table 1.

The results of these drying tests are presented in the form of graphs. Figure 3 shows the drying curves and the temperature plots for two representative samples No. 1 and 2 , dried with different frequencies of air temperature.

Drying curves presented in Fig. 3a, b clearly show the characteristic stages of drying: the heating period $(\mathrm{H})$, the constant drying rate period (CDRP), and the falling drying rate period (FDRP) [33]. The temperature plots show the programmed temperature changes of the drying medium (heating-cooling) caused by alternate supply of cold and hot air. The straight section of the drying curve indicates the CDRP when the air temperature is constant $\left(T=100{ }^{\circ} \mathrm{C}\right)$ and the sample weight loss is constant in time.

During the cold part of the cycle, the rate of drying decreased, enabling a constant moisture distribution throughout the whole material volume. At the end of the cooling period the inlet of cold air was closed and the heating of the chamber dryer was switched on again. The period "heating-cooling" was repeated twice with sample No. 1, and in the case of sample No. 2 it was
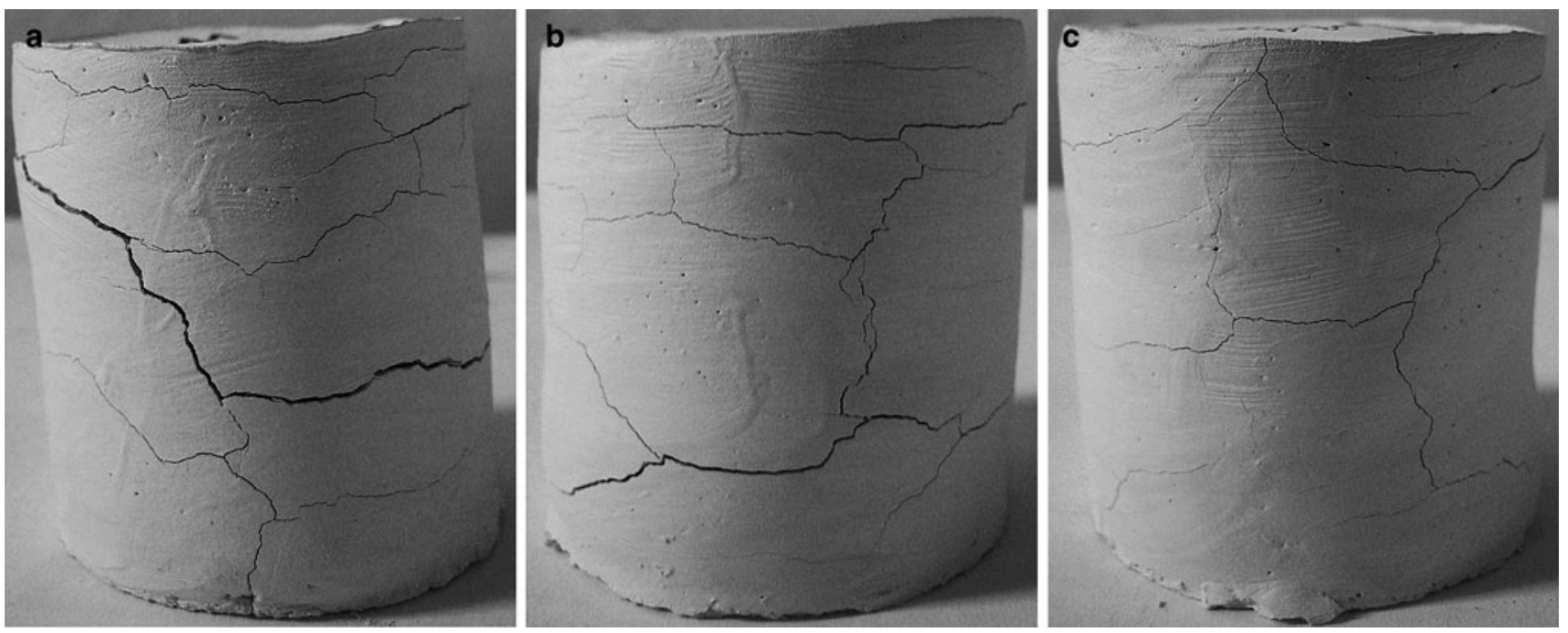

Fig. 4 Photos of samples dried at constant and variable air temperature: a constant conditions, $\mathbf{b} 2$ cooling cycles +2 heating cycles, $\mathbf{c} 3$ cooling cycles +3 heating cycles 

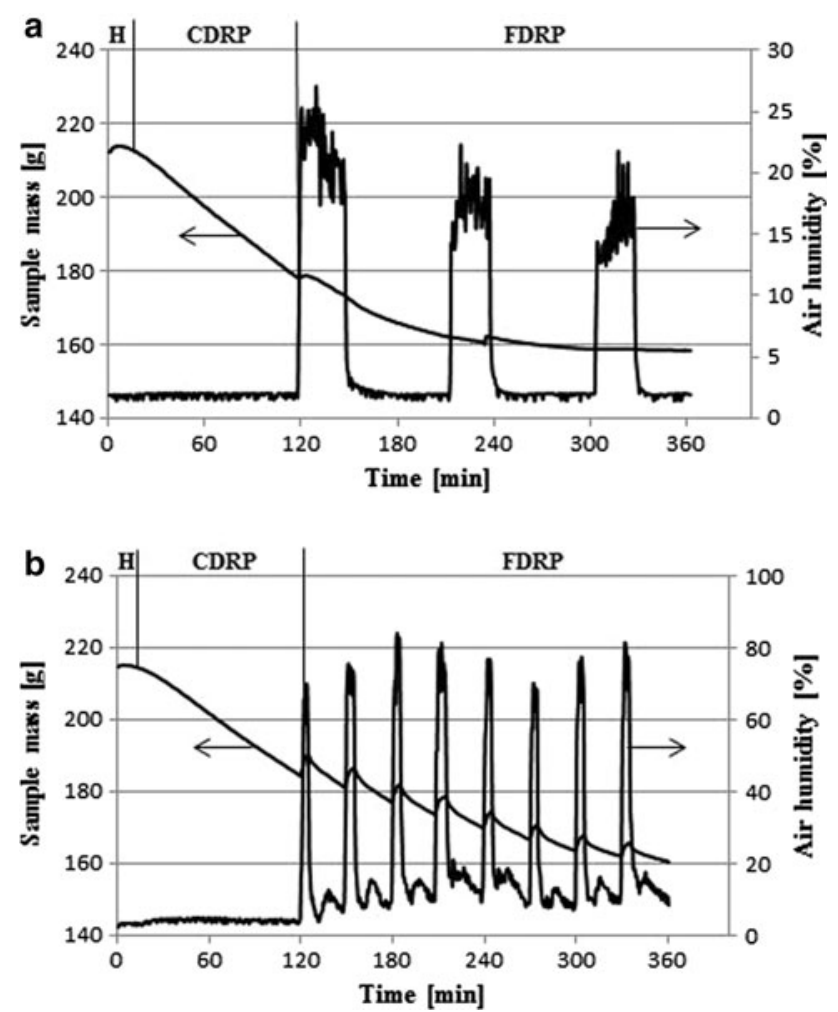

Fig. 5 Drying curves for periodical changes of the air humidity: a $30 \mathrm{~min}$ humidification $+60 \mathrm{~min}$ pause, b $5 \mathrm{~min}$ humidification +30 min pause

repeated three times. During the experiments the minimum air temperature was about $28{ }^{\circ} \mathrm{C}$ and the maximum about $130{ }^{\circ} \mathrm{C}$.

The advantage of drying in non-stationary conditions with respect to the stationary ones is visualized on the photos of dried samples presented in Fig. 4.
Figure 4a refers to drying at stationary conditions, while Fig. $4 \mathrm{~b}$ to drying at non-stationary condition with smaller frequency of temperature changes, and Fig. $4 \mathrm{c}$ with higher frequency of temperature changes. In the case of sample No. 2 (Table 1), a higher frequency of temperature changes was used, which resulted in a bit better quality of the sample surface (Fig. 4c), without lengthening the drying process.

It has been found that drying of kaolin-clay materials with changeable air temperature of higher frequency greatly improves the quality of the dried materials by reducing the crack formation. However, the quality of the dried in this way samples is still unsatisfied.

\subsection{Drying with variable frequencies of air humidity changes}

In the next stage of the experiments the influence of frequency of the air humidity changes on the kaolin quality was investigated. In Fig. 5 the drying curves of two representative samples No. 5 and 7 (Table 1) dried at changeable air humidity conditions are shown. These curves fully illustrate the moisture loss during drying and also the influence of air humidification intensity on the final mass of dried material. Supplying the vapor from the humidifier to the dryer chamber causes the vapor condensation on the colder sample surfaces each time. Thus the sample mass rises at the moment of humidification which causes also a slight lengthening of the drying process.

The maximum air humidity during drying of sample No. 5 reaches $22-27 \%$ on average. The same portion of vapor as in the previous case supplied at higher frequency (Fig. 5b) caused greater increase of the air humidity which reached maximum of about $84 \%$.
Fig. 6 Photos of samples dried at variable air humidity: a 3 humidification cycles +3 cycles without humidification, b 8 humidification cycles +8 cycles without humidification
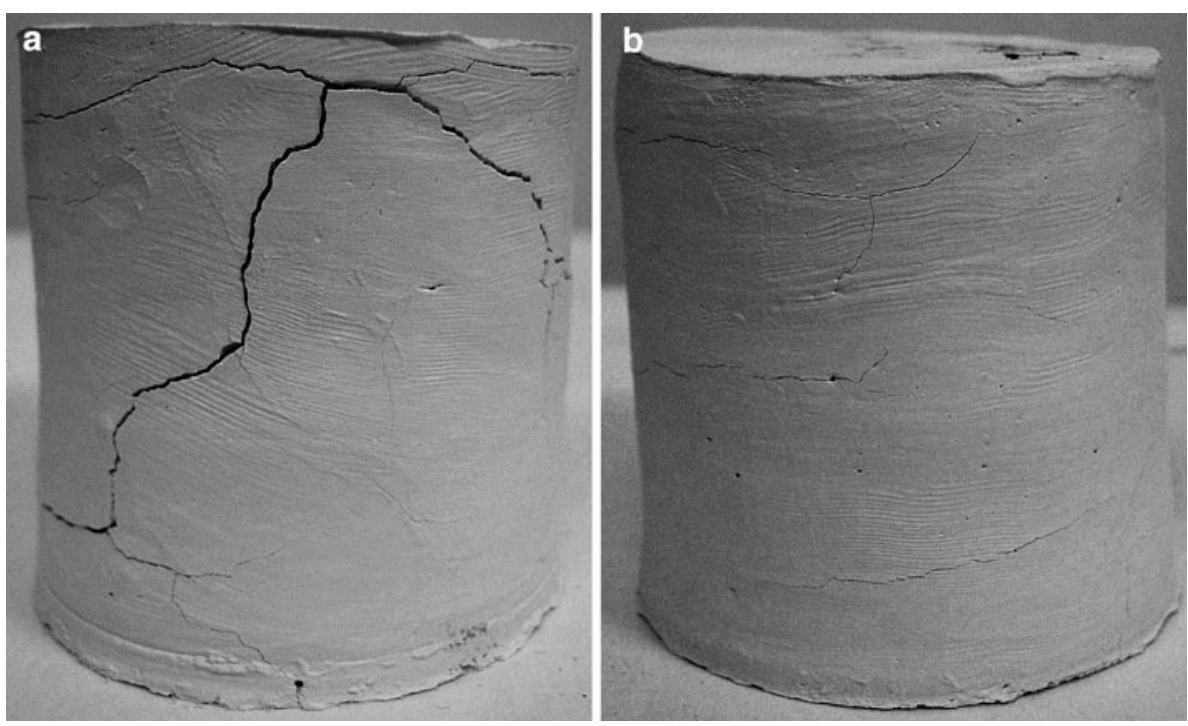

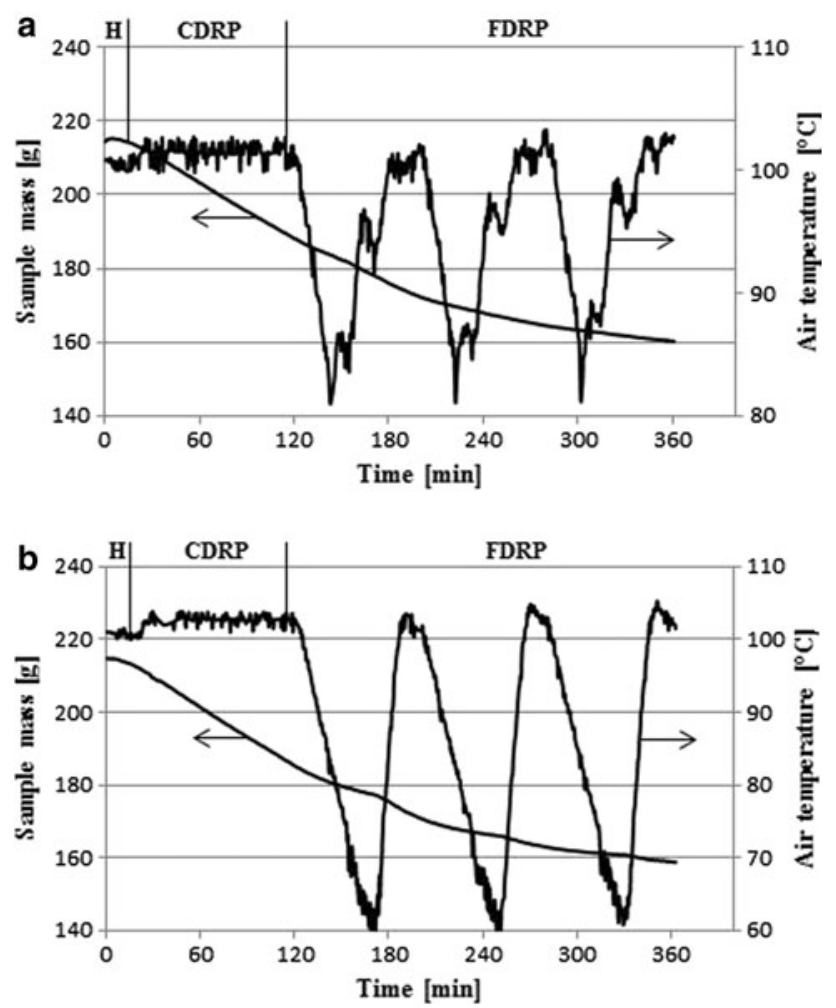

Fig. 7 Drying curves for the periodical air temperature changes: a amplitude $100-80{ }^{\circ} \mathrm{C}$, b amplitude $100-60{ }^{\circ} \mathrm{C}$

The external appearance of the samples dried with different air humidity changes is shown in Fig. 6.

The best quality samples were obtained using a greater number of short-lived cycles of humidification (Fig. 6b). A significant difference in the number of cracks on the sample surfaces between the samples seen in Fig. $6 \mathrm{a}, \mathrm{b}$ indicates that the higher frequency of the air humidity changes leads to better quality of dried products at the cost of a bit longer drying time.

\section{Drying with different amplitudes of drying parameters}

In the second part of the studies the influence of the amplitude of changes in drying medium parameters on the quality of the kaolin samples was investigated. The series of eight tests was realized on samples No. 2 and 7 (Table 1). The air cooler and the vapor humidifier were applied in a similar way as before, that is, they were used after $120 \mathrm{~min}$ of the drying process.

\subsection{Drying with different temperature amplitudes}

The results of drying tests with different amplitude sizes of air temperature are presented in the form of drying curves in Fig. 7a, b.

The analysis of drying curves for the samples No. 9 and 10 shows that $20^{\circ} \mathrm{C}$ difference in temperature between the programmed amplitudes did not cause any changes in the drying rate. In both cases a similar weight loss about $55 \mathrm{~g}$ was observed.

The visual appearance of samples dried with different temperature amplitudes is presented in Fig. 8.

As it follows from Fig. 8, a similar quality of the samples were obtained using different temperature amplitudes. The quality of these samples do not differentiate to much from those dried at different frequencies of heating and cooling periods (Fig. 4).
Fig. 8 Photos of samples dried at different amplitudes of air temperature: a amplitude $100-80{ }^{\circ} \mathrm{C}$, b amplitude $100-60{ }^{\circ} \mathrm{C}$
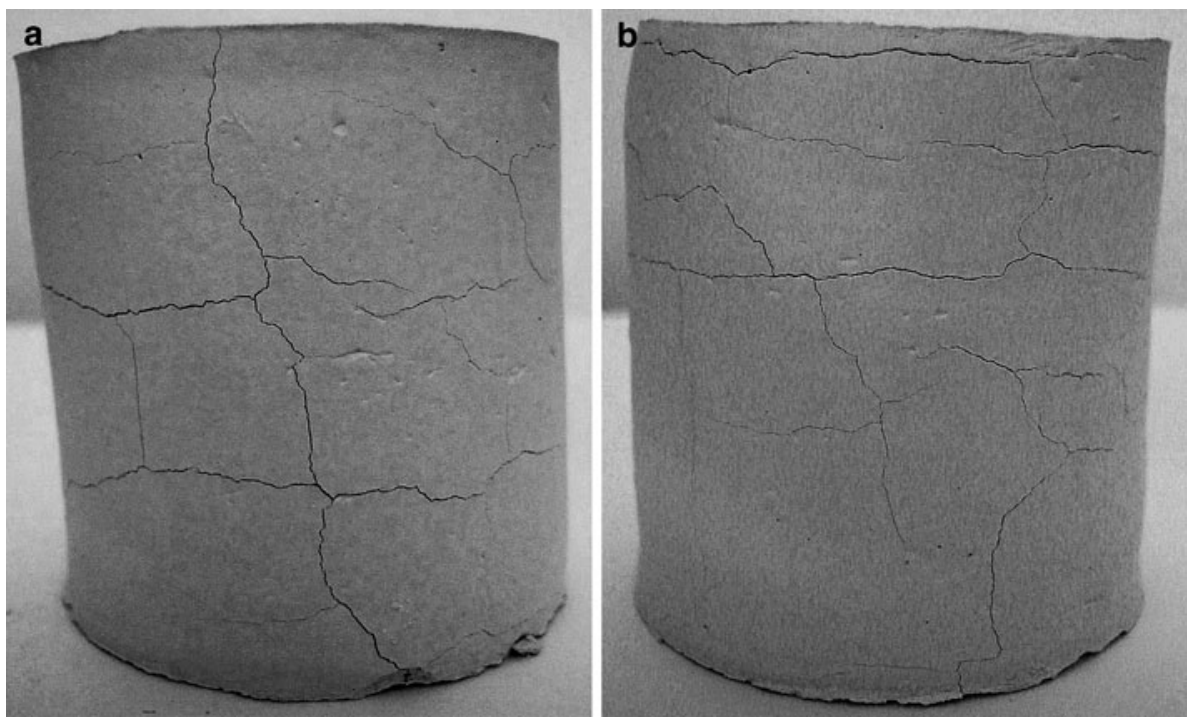

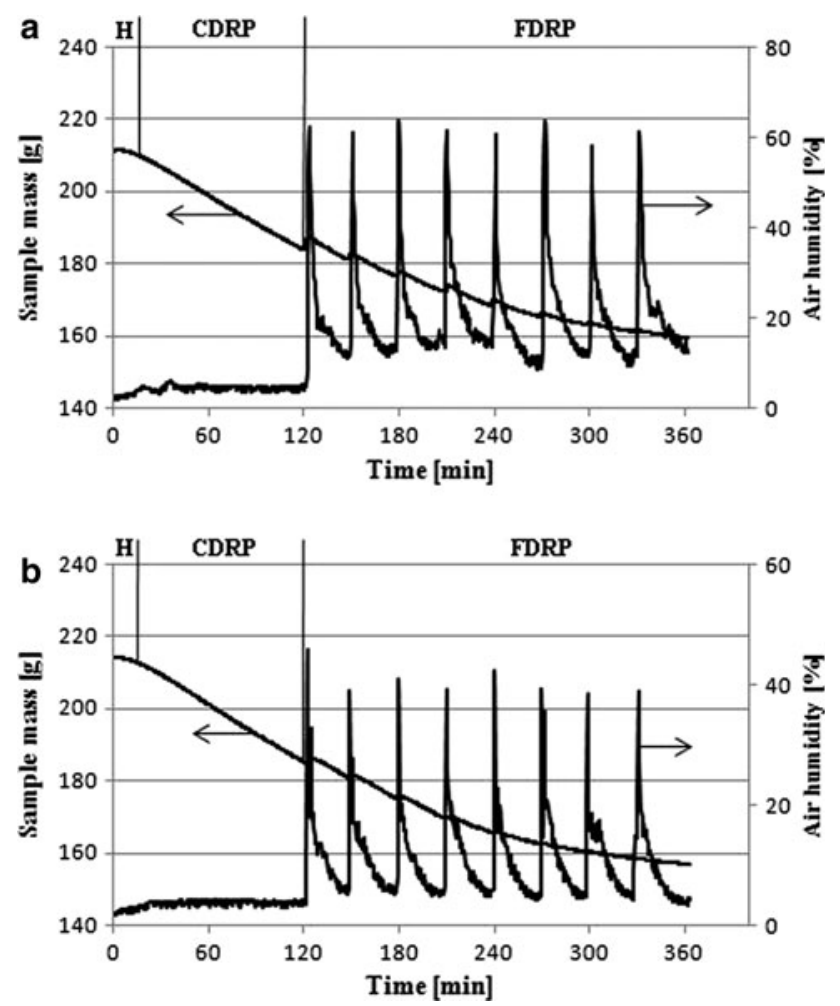

Fig. 9 Drying curves for periodical changes of air humidity: a amplitude $15-60 \%$, b amplitude 5-40\%

\subsection{Drying with different air humidity amplitudes}

The drying curves for the samples No. 11 and 12 dried at different air humidity amplitudes are shown in Fig. 9.

It has been noticed that supply of the vapor to the dryer chamber results in vapor condensation on the colder samples surfaces causing an increase of moisture content in the samples, and thus also lengthens the drying time.
Figure 9a clearly shows that higher level of the air humidity retards the evaporation of water from the material. However, the proposed process with periodical changes of air humidity having amplitude between 15 and $60 \%$ with the sequence $5 \mathrm{~min}$ humidification and $30 \mathrm{~min}$ pause gives the possibility of obtaining a good quality product. The photos of the samples dried in this way (Fig. 10) justify such a proposal.

As it is seen in Fig. 10, the kaolin samples dried at different amplitudes of air humidity differ significantly from each other. The sample characterized in Fig. 10b reveals deep cracks which were formed probably later during the (FDRP), when an intensive moisture evaporation from the dried sample occurred. So, the $20 \%$ difference between the air humidity amplitude significantly affects the drying process, that is, reduces significantly the drying stresses and improves the product quality.

\section{Monitoring of material destruction with $\mathrm{AE}$}

Figure 11 shows the AE descriptor expressing the AE energy per $30 \mathrm{~s}$ interval for the process with variable temperature (sample No. 9), and the sample photos showing the development of sample destruction in the course of drying.

Most impulses occurred in the FDRP, but the early cracking was observed after 240 min of a drying process. The greatest AE energy per $30 \mathrm{~s}$ equal to $0.079 \mathrm{mV}^{2} \mathrm{~s}$ was recorded after $300 \mathrm{~min}$ of drying. The subsequent $\mathrm{AE}$ energy peaks on the graph in Fig. 11 are the results of sample cracking, as it shows the photograph taken in $360 \mathrm{~min}$ of the process.

Figure 12 presents the registered signals for kaolin sample No. 10 dried at periodical air humidity changes. Below the graph of AE energy per $30 \mathrm{~s}$, the photographs
Fig. 10 Photos of the samples dried at different amplitudes of air humidity: a amplitude $15-60 \%$, b amplitude 5-40\%
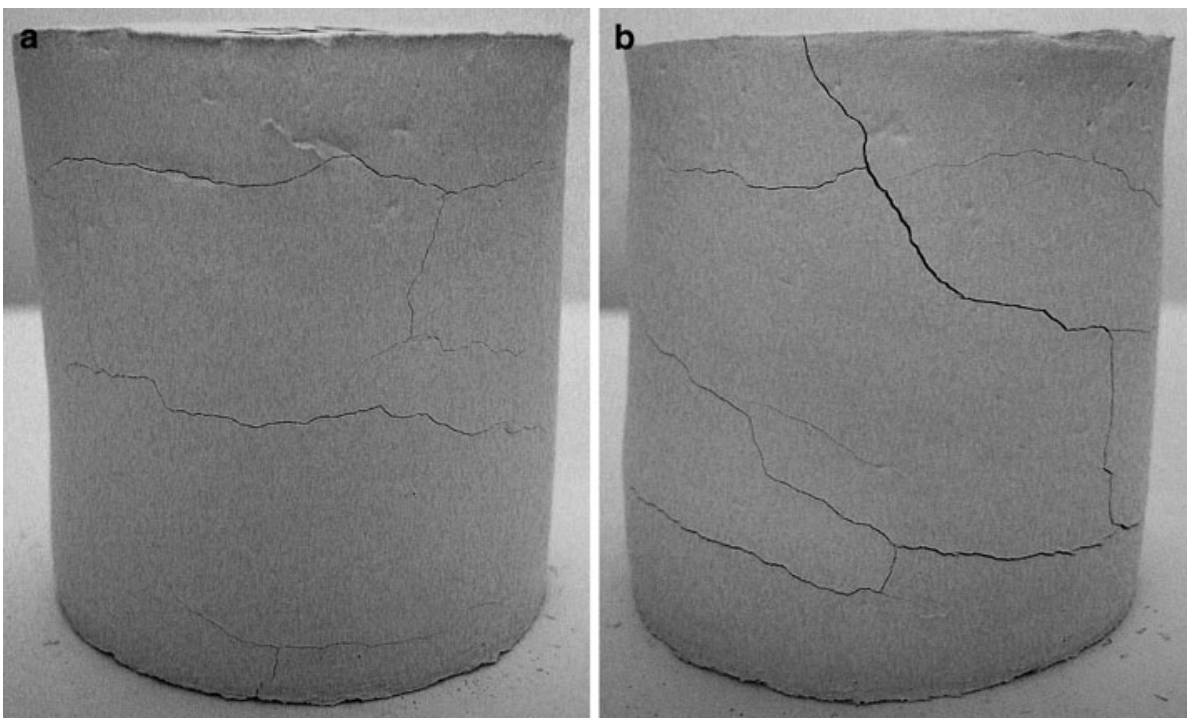


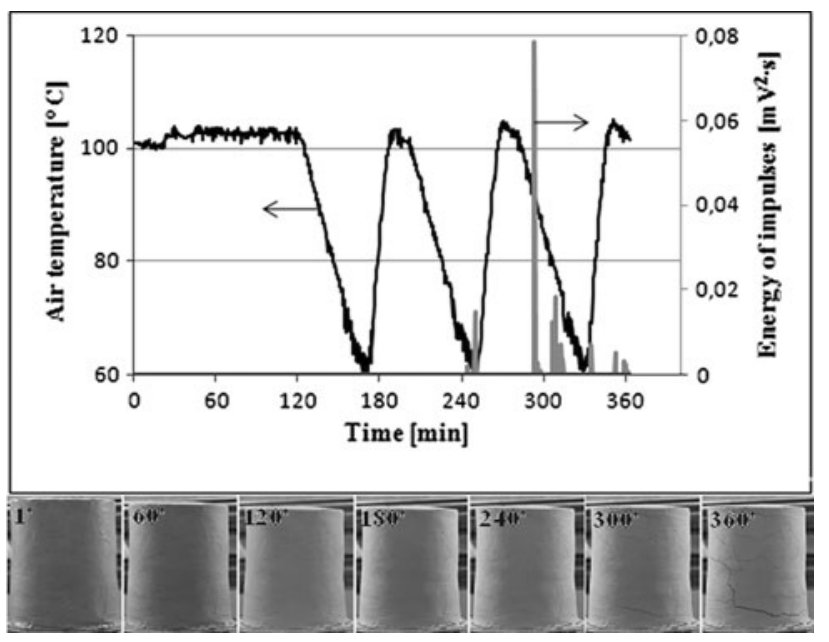

Fig. 11 Development of kaolin sample destruction during drying at variable air temperature

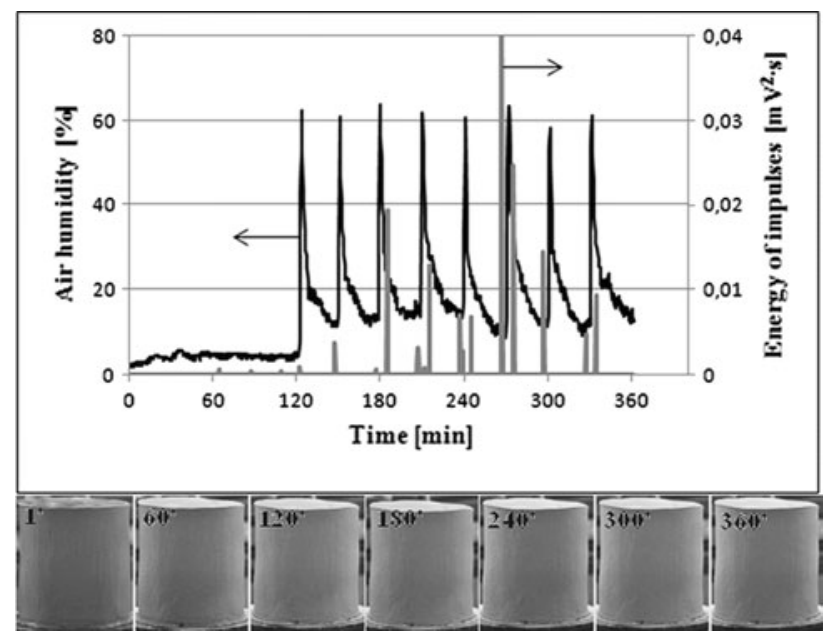

Fig. 12 Development of kaolin sample destruction during drying at variable air humidity

illustrating the development of kaolin sample destruction are shown.

In the case of the drying with variable air humidity much more AE signals were recorded, but they are characterized by lower energy than in the tests with variable temperature. The highest energy peak of $0.04 \mathrm{mV}^{2} \mathrm{~s}$ appeared in $267 \mathrm{~min}$ of drying. Absence of bigger cracks on the sample surface, as it is evidenced by the series of photographs shown in Fig. 12, proves better quality of the dried material.

It has to be mentioned that each startup of the humidifier resulted in a rapid growth of the AE impulses. Moreover, it has been found that the peaks on the graph (Fig. 12) are primarily the result of humidifier operation, and the vapor supplied to the dryer chamber really disturbs the monitoring of sample destruction through the EA method.

\section{Conclusions}

The tests concerning non-stationary drying of kaolin clay materials have shown that the methodology of drying with variable drying conditions has an essential influence on the quality of dried products. It has been proven that an appropriate programming of drying medium temperature and humidity changes may significantly reduce destruction of dried products. In particular, the dried material showed itself to be very susceptible to changes of the humidity both the frequency and amplitude changes. The best solution from the kaolin clay quality point of view is to use drying with short (few minutes) periodical air humidification.

An increase in frequency of the air temperature changes in the dryer chamber improved also to a certain degree the quality of the dried material, however, an increase in the temperature amplitude was not effective. In the case of periodical changes of the air temperature, the best sequence of changes combines the short-lived periods of heating and longer cooling periods.

The acoustic emission (AE) is a good tool for control of the dried material destruction, but due to its high sensitivity it is not recommended to use with a humidifier working at the same time.

It has been shown that the quality of dried samples depends significantly on the frequency and the amplitude of the air temperature and humidity alteration in the chamber dryer. It has to be added that the periodically changing drying parameters did not lengthen significantly the drying time with respect to drying at stationary conditions.

Acknowledgments This work was carried out as a part of the research project No. 32-127/2012 DS-PB sponsored by the Poznań University of Technology.

Open Access This article is distributed under the terms of the Creative Commons Attribution License which permits any use, distribution, and reproduction in any medium, provided the original author(s) and the source are credited.

\section{References}

1. Sherer G (1990) Drying theory. J Am Ceram Soc 73(1):3-14

2. Salin JG (2003) A theoretical analysis of timber drying in oscillating climates. Holtzforschung 57:427-432

3. Kowalski SJ, Moliński W, Musielak G (2004) The identification of fracture in dried wood based on theoretical modeling and acoustic emission. Wood Sci Technol 38:35-52

4. Herrithsch A, Dronfield J, Nijdam J (2008) Intermittent and continuous drying of red-beech timber from the green conditions. Proceedings of the 16th international drying symposium. B, pp 1114-1121

5. Raisul IM, Mujumdar AS (2004) Periodic multimode batch drying of heat-sensitive materials: engineering applications of the 
diffusion equation. In: Mujumdar AS (ed) Dehydration of products of biological origin. Science Publishers, Enfield, pp 93-133

6. Chou SK, Chua KJ, Mujumdar AS, Hawlader MNA, Ho JC (2000) On the intermittent drying of an agricultural product. Trans Inst Chem Eng 78(Part C):193-203

7. Chua KJ, Chou SK, Ho JC, Mujumdar AS, Hawlader MNA (2000) Cyclic air temperature drying of guava pieces: effects on moisture and ascorbic acid contents. Trans Inst Chem Eng 78(Part C):72-78

8. Pan YK, Zhao LJ, Hu WB (1999) The effect of temperingintermittent drying on quality and energy of plant materials. Drying Technol 17(9):1795-1812

9. Pan YK, Zhao LJ, Hu WB (1999) Intermittent drying of carrot in a vibrated fluid bed: effect on product quality. Drying Technol 17(10):2323-2340

10. Chen YL (1996) Simulation of paddy rice drying for intermittent drying pattern. Mem Coll Agric 36(2):128-141. National Taiwan University, Taipei, Taiwan, ROC

11. Shei HJ, Chen YL (1998) Intermittent drying of rough rice. Drying Technol 16(3-5):839-851

12. Kowalski SJ, Musielak G, Rybicki A (1992) Shrinkage stresses in dried materials. Eng Trans 40(1):115-131

13. Kowalski SJ, Rybicki A (1994) Interaction of thermal and moisture stresses in materials dried convectively. Arch Mech 46(3):251-265

14. Kowalski SJ, Rybicki A (1996) Drying stress formation by inhomogeneous moisture and temperature distribution. Transp Porous Med 24:139-156

15. Kowalski SJ (2003) Thermomechanics of drying processes. Springer, Heldelberg

16. Thomkapanich O, Suvarnakuta P, Devahastin S (2007) Study of intermittent low-pressure superheated steam and vacuum drying of a heat-sensitive material. Drying Technol 25(1):205-223

17. Bon J, Kudra T (2007) Enthalpy-driven optimization of intermittent drying. Drying Technol 25(1-2):523-532

18. Smith SA, Langrish TAG (2008) Multicomponent solid modeling of continuous and intermittent drying of Pinus radiata sapwood below the fiber saturation point. Drying Technol 26(7):844-854
19. Kowalski SJ, Pawłowski A (2008) Drying in stationary and nonstationary conditions. Chem Process Eng 29:337-344

20. Kowalski SJ, Pawłowski A (2010) Drying of wet materials in intermittent conditions. Drying Technol 28(5):636-643

21. Kowalski SJ, Pawłowski A (2011) Intermittent drying of initially saturated porous materials. Chem Eng Sci 66:1893-1905

22. Kowalski SJ, Pawłowski A (2010) Drying of wood with air of variable parameters. Chem Process Eng 31:135-147

23. Zhang D, Mujumdar AS (1992) Deformation and stress analysis of porous capillary bodies during intermittent volumetric thermal drying. Drying Technol 10(2):421-443

24. Li YB (1999) Study on rough rice fissuring during intermittent drying. Drying Technol 17(9):1779-1793

25. Jumach R, Mujumdar AS, Raghavan GSV (1996) A mathematical model for constant and intermittent batch drying of grains in a novel rotating jet spouted bed. In: Turner I, Mujumdar AS (eds) Mathematical Modelíng and Numerical Techniques ín Dryíng Technology. Marcel Dekker, New York, pp 339-380

26. Shei HJ, Chen YL (2002) Computer simulation on intermittent drying of rough rice. Drying Technol 20(3):615-636

27. Kowalski SJ, Pawłowski A (2010) Modeling of kinetics in stationary and intermittent drying. Drying Technol 28(8):1023-1031

28. Kowalski SJ, Pawłowski A (2011) Intermittent drying: energy expenditure and product quality. Chem Eng Technol 34(7): $1123-1129$

29. Kowalski SJ, Pawłowski A (2011) Energy consumption and quality aspect by intermittent drying. Chem Eng Process Process Intensif 50(4):384-390

30. Rajewska K, Kowalski SJ (2002) Acoustic emission as a method of monitoring of fracture phenomena in dried materials. Diagnostics 27:95-101 (in Polish)

31. Kowalski SJ, Banaszak J, Rajewska K (2003) Acoustic emission in dried materials. Chem Eng Apparatus 4:3-8 (in Polish)

32. Kowalski SJ (2010) Control of mechanical processes in drying. Theory and experiment. Chem Eng Sci 65:890-899

33. Strumiłło CZ (1983) Foundations of the theory and technology of drying, 2nd edn. WNT Warsaw (in Polish) 